\title{
Synthesis of biochar conjugated Schiff base composites and their enhanced antimicrobial activity against five pathogenic organisms
}

\author{
Felix Sunday Nworie ${ }^{凶}$, Frank Ik. Nwabue, Wilberforce Oti, Confidence Obasi, \\ Chinwe Ejim and Blessing Nwafor
}

Department of Industrial Chemistry, Ebonyi State University, Abakaliki, Nigeria

\section{Article info}

\section{Article history:}

Received: $30^{\text {th }}$ July 2020

Accepted: $23^{\text {rd }}$ November 2020

\section{Keywords:}

Antimicrobial/biocidal evaluation

Biochar

Pathogens

Plantain peel

Rice husk

Schiff base

\begin{abstract}
The search for antimicrobial drug of high bio-efficacy not prone to multiple microbial resistance has been on the rise in recent time. This study focused on the preparation, characterization and antimicrobial evaluation of Schiff functionalized $\mathrm{HNO}_{3}$ activated plantain peel and rice husk biochar against five pathogenic bacteria. The activated rice husk and plantain peel biochar were characterized using Braunauer-Emmett-Teller, X-ray diffraction and Fourier transform infra-red spectroscopy. Based on the result, the activated rice husk and plantain peel biochar were amorphous and crystalline respectively with pore surface area and pore size for activated rice husk and plantain peel biochar as 9.369 and $27.32\left(\mathrm{~m}^{2} . \mathrm{g}^{-1}\right)$ and 8.790 and $16.65\left(\mathrm{cc} . \mathrm{g}^{-1}\right)$, respectively. The Fourier transform infra-red spectroscopy result indicated bonds, such as $-\mathrm{OH}, \mathrm{C}=\mathrm{O}$ and $-\mathrm{N}-\mathrm{H}$, where actual chelation and electrostatic attraction mechanism are prevalent responsible for antimicrobial potency. The cell bioactivity was hampered due to permeation of the biocidal agents, cell membrane disruption and generation of reactive oxygen species enhanced by conjugation of Schiff base based biochar to the microbial cell wall leading to death of microbes. The ease of Schiff base release and reusability of the nanocomposite favors the product as an efficient, low cost, effective and promising nanocomposite for decontamination of bacteria infested media.
\end{abstract}

(C) University of SS. Cyril and Methodius in Trnava

\section{Introduction}

Contamination of water by microbial agents is a serious global challenge threatening human health and aquatic safety. Current disinfection method though reliable for efficient containment of microbial infection but the by product, which is seemingly deleterious calls for concern. Similarly, the emergence of antimicrobial resistance among pathogenic organisms which makes treatment difficult for some life-threatening infections have been on the increase prompting serious concern on the subject. Currently, it is predicted that if the trend of antimicrobial resistance remains unabated, more people are likely to die of drug-resistant infections than cancer by 2050. Proliferation of pathogenic organisms is common in all areas of human endeavour, such as food and other production industries, soils and aqueous media. In most African agrarian villages and municipalities Nigeria inclusive, illicit deposition and disposal of waste has become the bane. Not only that these wastes are improperly and indiscriminately deposited, there is no efficient and effective means of management, control or conversion into useful products. Most 
agricultural by-products are termed waste simply because it is not useful to the locality or there is no further use of such product and they are of serious environmental concern (Tang et al. 2020). Most of the wastes have been noted to be useful to man and other animals after conversion to other form (Chen et al. 2019). Specifically, plantain peel waste has been noted to have medicinal properties as bioactive compounds, such as flavonoids, tannins, alkaloids, glycosides, and terpenoids are present and exert pharmacological effect as an antioxidant, antidiabetic, anti-inflammatory and antibiotic substance (Okareh et al. 2015). Some bioactive agents (norepinephrine, dopamine, and serotonin) were also discovered by researchers in the peels and pulp with the norepinephrine and dopamine relevant in elevating blood pressure whereas serotonin impairs gastric secretion and stimulates the smooth muscle of the intestines (Asuquo and Udobi 2016). Several studies have noted that peels of plantain and rice husk exhibit antifungal and antibiotic properties (Kala et al. 2015; Asuquo and Udobi 2016; Banji and Adebayo 2020). Abakaliki, Nigeria is known for rice production and the management of the rice husk a by-product of the milling exercise has been a problem for several decades. The rice husk has led to wide fires attacking vegetation and increasing the emission of carbon (IV) oxide into the atmosphere. Environmental pollution is increased if the rice husk is burnt to generate energy (used as fuel) rendering the process environmentally unfriendly and a search for alternative friendly and environmentally benign and palatable method of managing the waste becomes imminent.

Biochar a carbon-rich product obtained when biomass materials, such as wood, manure or leaves is heated in a container with little or no available air (Oxygen) is currently under study by numerous researchers because of their wide applications in different areas of life (Nworie et al. 2019). Consequently, biochar generally produced under thermal decomposition of organic material under limited supply of oxygen $\left(\mathrm{O}_{2}\right)$ and at relatively low temperature $\left(<700{ }^{\circ} \mathrm{C}\right)$ is germane in soil management to regulate the fertility of the soil and avert effect of climate change, carbon sequestration to keep the environment benign reducing or eliminating greenhouse gases, immobilization of pollutants and metal adsorption through adsorption of the pollutants and metal ions on the porous surfaces and exposed active functional groups by activation, and other miscellaneous applications (Ghorbani and Eisazadeh 2015). Several studies have indicated that biochar is effective and efficient not only in soil amendment but also in sequestration of carbon, pollutant removal from soil and aqueous media and other miscellaneous application (Ghorbani and Eisazadeh 2015). Recently, it was reported that conversion of biomass into biochar not only result in creating renewable energy (Synthetic gas and bio oil) but has succeeded in limiting the amount of $\mathrm{CO}_{2}$ in the atmosphere which as well is a means of environmental cleaning and purification (Zhao et al. 2018; Chen et al. 2020). To increase the functionality, effectiveness, efficiency and modify electronic property as well as molecular size of the biochar, there is need for functionalization of the biochar using oxygen or nitrogen containing specie.

A Schiff base, imine, aldimine or azomethine is a compound with the general structure $\mathrm{R}_{2} \mathrm{C}=\mathrm{NR}^{\prime}$ serve as ligands which stabilize central metal ions in low oxidation state as they form co-ordination complexes with the metal ions useful in many applications as catalysts, antimicrobial agents and other miscellaneous applications (Nworie 2018). Bis(salicylidene)ethylenediamine(SALEN) and bis(acetylacetonato) ethylenediamine (ACACEN) are both popular chelating tetradentate Schiff bases very important in homogeneous catalysis and Co-ordination Chemistry. Their incorporation or functionalization into biochar for antimicrobial evaluation is yet unknown but the presence of $\mathrm{N}_{2} \mathrm{O}_{2}$ atoms in their moiety is believed to provide enough oxygen and nitrogen functionalities imparting multilateral properties to the composite. Functionalization of biochar surface is currently a promising and emerging area of research due to increased effectiveness, permeability, ease of release, recyclability, efficiency, stability and multiple action related properties of the composite material. This research is imminent especially now that multi-resistant bacterium or the super bugs are on the increase with scientists exploring several avenues to avert or arrest this misnomer that have led to loss 
of money and delay in handling diagnosed ailments. This study is aimed at (i) developing a low cost, eco-friendly biocidal agent using biochar and Schiff bases (SALEN and ACACEN), (ii) characterizing the activated biochar, (iii) regeneration/reusability of the used biocidal agent.

\section{Experimental}

\section{Equipment}

Braunauer-Emmett-Teller (BET) was measured using Micromeritics ASAP 2020 system. X-ray diffraction(XRD) pattern was obtained on a Bruker ${ }^{\circledR}$ D8 Discover diffractometer, equipped with a Lynx Eye detector, under $\mathrm{Cu}-\mathrm{Ka}$ radiation

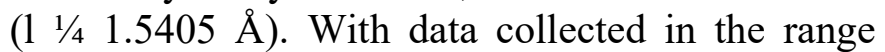
of $2 \theta=10$ to $100^{\circ}$, scanning rate at $0.010^{\circ} \cdot \mathrm{min}^{-1}$, 192 s per step and samples placed on a zero background silicon wafer slide. Cary 630 Agilent Technologies, USA was used for Fourier Transform Infra-Red Spectroscopy (FTIR) analysis.

\section{Biochar sample collection, preparation and activation}

Plantain peels was collected from Abakaliki meatmarket while rice husk was collected from Abakaliki rice mill cleaned and kept in dried polyethene bags. The samples (rice husk and plantain peels) were washed with distilled water, cleaned of soil and other impurities, sun dried to reduce moisture content for 7 days and then oven dried at $60{ }^{\circ} \mathrm{C}$ for $6 \mathrm{~h}$.

The samples were carbonized following the procedure reported elsewhere (Nworie et al. 2019) at 550 and $580{ }^{\circ} \mathrm{C}$ for plantain peels and rice husk respectively in a $\mathrm{N}_{2}$ environment. The biochar formed were collected and activated using $0.1 \mathrm{M} \mathrm{HNO}_{3}$ for $1 \mathrm{~h}$ to yield nitric acid activated plantain peel biochar (APPB) and nitric acid activated rice husk biochar (ARHB) and products severally washed with deionized water to neutral $\mathrm{pH}$. The formed products were then oven dried at $110{ }^{\circ} \mathrm{C}$ for $12 \mathrm{~h}$ and kept to be used when desired.

\section{Synthesis of bis( salicylidene)ethylenediamine (SALEN)}

Ethylenediamine (22.475 g) was carefully added with stirring to $91.336 \mathrm{~g}$ of salicyladehyde in a $500 \mathrm{~cm}^{3}$ beaker. At initial stage, a yellow hot mixture was formed which translated to golden yellow cake on crystallization (Nworie and Nwabue 2017). Recrystallized of the product was effected with carbon tetrachloride to yield golden yellow crystals $(64.45 \%$ yield, M.P $\left.121 \pm 1^{\circ} \mathrm{C}\right)$.

\section{Synthesis of bis(acetylacetonato)ethylenediamine (ACACEN)}

Ethylenediamine (22.475 g) was gradually added with stirring to acetylacetone $(74.881 \mathrm{~g})$ in a $250 \mathrm{~cm}^{3}$ beaker with the two liquids previously chilled in ice salt mixture for $30 \mathrm{~min}$. The exothermic process was followed with formation of a whitish crystal which on addition of excess ethylenediamine gave deep golden yellow color. Crystallization was effected by stirring leading to a cream colored cake and the product recrystallized from carbon tetrachloride air dried (45.29\% yield, M.P $98 \pm 1{ }^{\circ} \mathrm{C}$ ).

\section{Impregnation of biochar}

Immobilization of the activated biochar was done by measuring $0.5 \mathrm{~g}$ of the activated biochar samples (plantain peel and rice husk) into two separate $250 \mathrm{~cm}^{3}$ conical flask. This was followed by the addition of $5 \mathrm{~cm}^{3}$ of $0.5 \%$ SALEN prepared by dissolving $5 \mathrm{~g}$ in $100 \mathrm{~cm}^{3}$ absolute ethanol and $5 \mathrm{~cm}^{3}$ of $0.5 \%$ ACACEN prepared by dissolving $5 \mathrm{~g}$ in $100 \mathrm{~cm}^{3}$ of distilled water. The mixture was stirred for $3 \mathrm{~h}$, filtered, washed to remove unreacted SALEN and ACACEN and oven dried at $60{ }^{\circ} \mathrm{C}$ for $1 \mathrm{~h}$. The formed product between SALEN or ACACEN and activated plantain peel biochar regarded as SALEN or ACACEN functionalized activated plantain peel (S-APPB or A-APPB) and between SALEN or ACACEN and activated rice husk biochar known as SALEN or ACACEN functionalized activated rice husk biochar (S-ARHB or A-ARHB) were kept for further antimicrobial evaluation. 


\section{Antimicrobial susceptibility/screening test}

The antimicrobial activity of test samples against common pathogenic microbes, such as Staphylococcus aureus, Pseudomonas aeruginosa, Aspergillus sp., Candida sp. and Escherichia coli were evaluated using Kirby Bauer susceptibility test method (Nworie et al. 2018). The culture of the test bacteria were grown in nutrient broth (L-S biotech) and adjusted to $0.5 \mathrm{McF}$ arland turbidity standards with the inoculums aseptically swabbed on the surface of Mueller Hinton agar plates using sterile swab sticks. Commercially available single antibiotic disc (TM Media, Laboratory Chemicals, CAS 7177 48-2, Code 3007) impregnated with ampiclox were aseptically placed on the Mueller Hinton agar plates as control. Both the samples and the control were incubated at $37{ }^{\circ} \mathrm{C}$ for $18-24 \mathrm{~h}$ and the diameters of inhibition zone for the four separate determinations were recorded.

The biocidal activities of the functionalized biochar were executed in a sterile agar plates with single plates used for a particular bacterial strain. In the experiment, $50 \mu \mathrm{L}$ of $2 \mu \mathrm{g} . \mathrm{L}^{-1}$ test samples in agar medium was added to the first plate, followed by separate additions after four serial dilutions. Consequently, $50 \mu \mathrm{L}$ of the prepared bacterial cultures were separately added to the plates as previously stated and the plates incubated at $37{ }^{\circ} \mathrm{C}$. The diameter of inhibition and comparison to standard were recorded. The minimum inhibitory concentration (MIC) was evaluated using the agar well dilution method by varying the concentrations of test samples between $5-20 \mu \mathrm{g} . \mathrm{L}^{-1}$ and test solution in agar medium incubated at $37^{\circ} \mathrm{C}$.

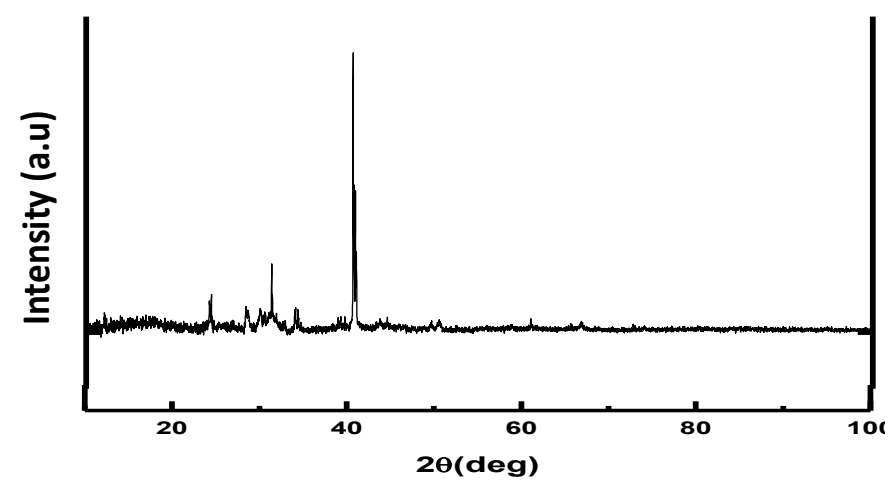

Fig.1. X-ray diffraction pattern of activated plantain peel biochar.
The diameter of inhibition was recorded. The level of significance at $P<0.05$ was statistically determined. Regeneration and reusability of the used biochar and composites was effected using different $\mathrm{HCl}$ concentrations and varied time of equilibrations and four biocidal-acid decimation cycle.

\section{Results and Discussion}

The XRD ( $\mathrm{Cu}-\mathrm{Ka}$ radiation) patterns of ARHB and APPB are shown in Figs. 1 and 2, respectively. The XRD diffraction pattern of ARHB showed one single strong peak at $2 \theta=18-30^{\circ}$, two well resolved broad peaks and a less resolved broad peak at $2 \theta=70-80^{\circ}$ which is characteristic of amorphous silica phase arising from mesoporous structure of nanocomposite observed in biochar carbonized below $600{ }^{\circ} \mathrm{C}$ (Pulido-Novicio et al. 2001; Zhao et al. 2011). A peak for potassium oxide is usually found at $2 \theta=29-31$ (Jindapon et al. 2015). Some authors (Yang et al. 2019) shown that biochar surfaces conjugated with metal oxides exert increased biocidal activity. The XRD analysis indicated peaks of metal oxides which enhanced oxygen functionalities, increased reactive oxygen species, permeability of the biochar and composites leading to cell death. The XRD diffraction pattern of APPB indicated sharp peak at $2 \theta=40.53^{\circ}$ with observed decomposition of some species after biochar formation at $2 \theta=24.24$ and $31.31^{\circ}$ (Jindapon et al. 2015). Noticeable ordered crystallinity of the nanocomposite was observed and Scherrer equation (Eq. 1) (Zhao et al. 2018) was applied to determine the average crystallite size as $14.56 \mathrm{~nm}$ indicating the mesoporosity of the nanocomposite (Nworie et al. 2019):

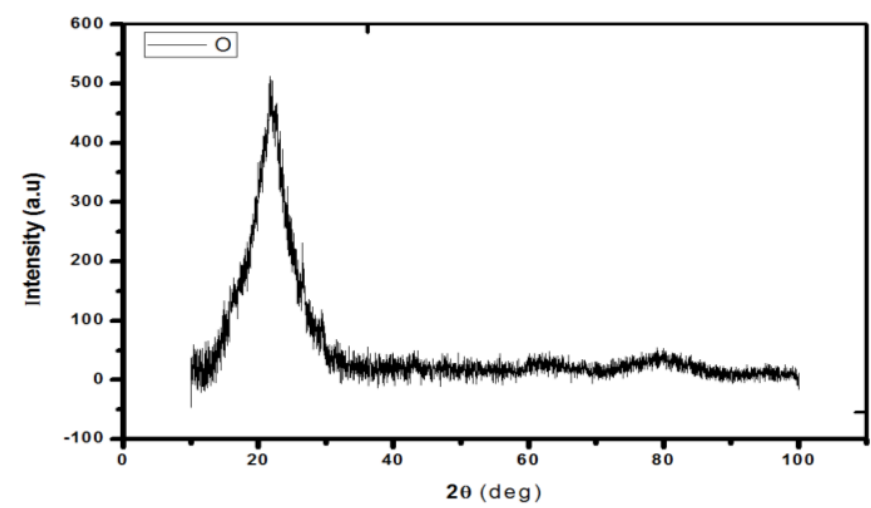

Fig. 2. X-ray diffraction pattern of activated rice husk biochar. 


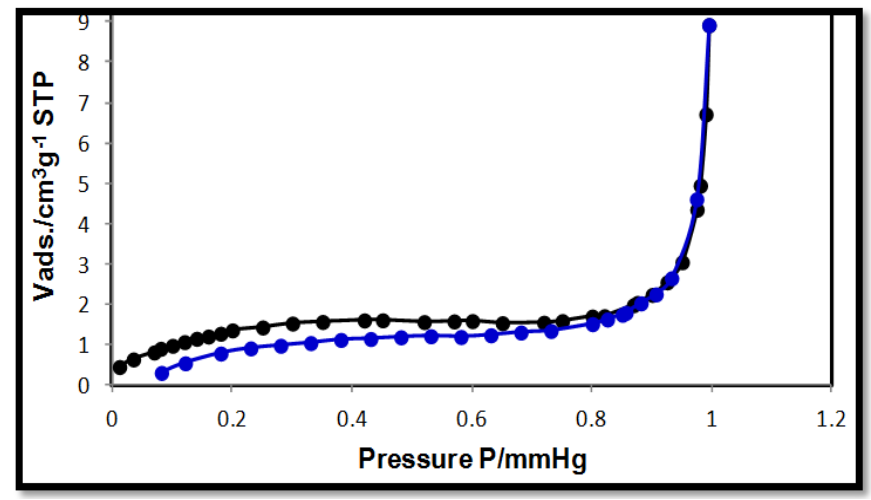

Fig. 3. Nitrogen adsorption/desorption BET plot of activated plantain peel biochar.

$$
d=\frac{\mathrm{K} \lambda}{\beta \operatorname{Cos} \theta}
$$

where $K$ is Scherer constant; $\beta$ is the full width at half maximum; $\lambda$ is the wavelength; and $\theta$ is Bragg angle.

Table 1. BET Surface area and pore size of activated biochar.

\begin{tabular}{lll}
\hline Sample & $\begin{array}{l}\text { Pore surface area } \\
{\left[\mathbf{m}^{2} \cdot \mathbf{g}^{-1}\right]}\end{array}$ & $\begin{array}{l}\text { Pore size } \\
{\left[\mathbf{c c .} \mathbf{g}^{-1}\right]}\end{array}$ \\
\hline $\begin{array}{l}\text { Activated rice husk } \\
\text { biochar }\end{array}$ & 9.369 & 27.32 \\
$\begin{array}{l}\text { Activated plantain } \\
\text { peels biochar }\end{array}$ & 8.790 & 16.65 \\
\hline
\end{tabular}

Brunauer-Emmett-Teller (BET): Surface area and pore size analysis

It has been noted (ALOthman 2012) that in any BET analysis, the effective area where capturing of micro-organism can occur under controlled experimental conditions for mesoporous, macroporous and nonporous solid is the probe accessible region. The nitrogen adsorption/desorption isotherms of the activated illustrated by the BET isotherm plot are shown in Figs. 3 and 4 for ARHB and APPB respectively. Clear analysis of the isotherm indicated that it is mesoporous and similar to a type IV IUPAC classical isotherm classification (ALOthman 2012). In ARHB and APPB, the hysteresis loop was observed over the pressure range of $0.9-1.0$ consistent of type HI common when the pore size is beyond a known critical width wider than $4 \mathrm{~nm}$ observable in networks of ink bottle pores (ALOthman 2012). There was observed shift in the $\mathrm{STPg}^{-1}$ for the isotherm of ARHB and APPB

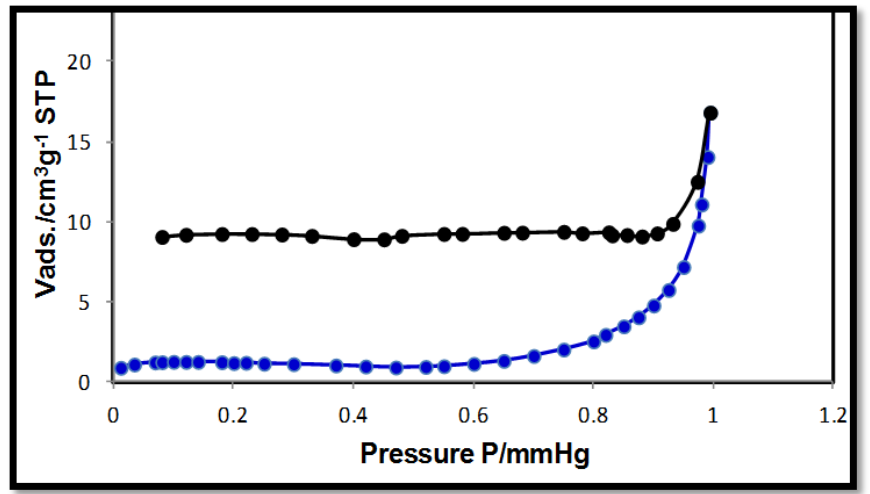

Fig. 4. Nitrogen adsorption/desorption BET plot of activated rice husk biochar.

upwards by 8 and $15 \mathrm{~cm}^{3}$ respectively. The surface area $\left(\mathrm{m}^{2} \cdot \mathrm{g}^{-1}\right)$ and pore size $\left(\mathrm{cc} \cdot \mathrm{g}^{-1}\right)$ was 8.790 and 16.69 for APPB respectively and 9.369 and 27.32 for ARHB respectively. It could be observed from the BET analysis presented in Table 1 that ARHB has greater pore surface area and pore size than the APPB. The large surface area per gram of a sample of the biochar showed increased ability for micro-organisms destruction as they get denatured on interaction with biochar (Nworie and Nwabue 2017).

\section{FTIR analysis of activated biochar samples}

The FTIR result of the APPB is shown in Fig. 5. A broad band representing hydroxyl group (-OH) was observed at $3,421 \mathrm{~cm}^{-1}$ for APPB attributed to $\mathrm{O}-\mathrm{H}$ stretching vibration due to intra and intermolecular hydrogen bonding (Kezerle et al. 2018; Nworie et al. 2020). The bands observed at 2,855 and $2,922 \mathrm{~cm}^{-1}$ is due to $-\mathrm{CH}_{2}$ groups (Banerjee and Chattopadhyaya 2017; Zhang et al. 2019). The band observed at $1,744 \mathrm{~cm}^{-1}$ could be that of the carbonyl group $(\mathrm{C}=\mathrm{O})$. Spectra band peaks observed at $1,461 \mathrm{~cm}^{-1}$ was assigned to $\mathrm{C}=\mathrm{C}$ phenol ring stretching vibration (Kezerle et al. 2018). The band observed at $1,371 \mathrm{~cm}^{-1}$ was assigned to $\mathrm{C}-\mathrm{N}$ stretching of the amine group (Banerjee and Chattopadhyaya 2017; Kezerle et al. 2018). The band that extends from 857 to $763 \mathrm{~cm}^{-1}$ was due to ester vibration of monosubstituted aromatic rings (Kezerle et al. 2018).

The FTIR spectra bands of ARHB is shown in Fig. 6. A broad band representing hydroxyl group $(-\mathrm{OH})$ was observed at $3,246 \mathrm{~cm}^{-1}$ and is due to intra and intermolecular hydrogen bonding 


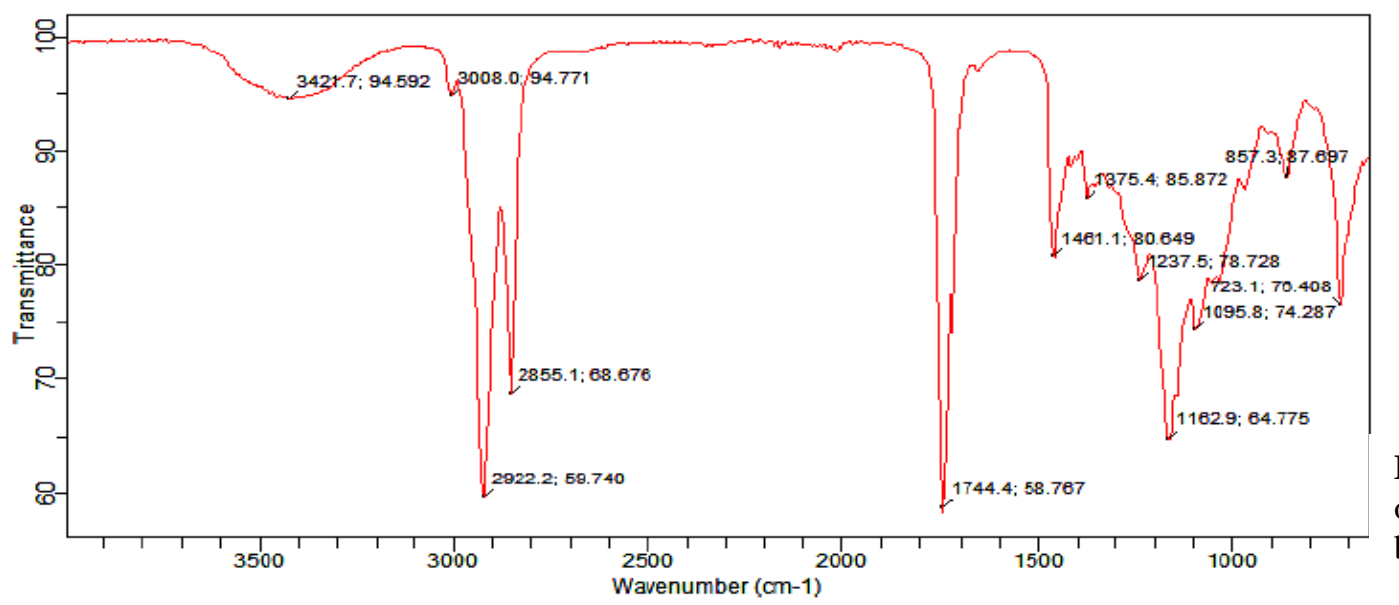

Fig. 5. FTIR spectra of activated plantain peel biochar.

(Kezerle et al. 2018). The bands observed at $2,922 \mathrm{~cm}^{-1}$ could be that of $-\mathrm{CH}_{2}$ groups (Banerjee and Chattopadhyaya 2017; Zhang et al. 2019; Nworie et al. 2020). The band observed at $1908 \mathrm{~cm}^{-1}$ was attributed to the carbonyl group $(\mathrm{C}=\mathrm{O})$. The peaks observed at $1,595 \mathrm{~cm}^{-\mathrm{I}}$ could be that of $\mathrm{C}=\mathrm{C}$ phenol ring stretching vibration from lignin (Kezerle et al. 2018). The intense band of $1,054.8 \mathrm{~cm}^{-\mathrm{I}}$ observed between $2,000-400 \mathrm{~cm}^{-\mathrm{I}}$ region was assigned to $\mathrm{C}-\mathrm{O}, \mathrm{C}=\mathrm{C}$ or $\mathrm{C}-\mathrm{C}-\mathrm{O}$ stretching vibration of ether group of cellulose, hemicellulose or lignin (Banerjee and Chattopadhyaya 2017; Kezerle et al. 2018; Nworie et al. 2019). The band that extends from 790 to $790.2 \mathrm{~cm}^{-1}$ was assigned to ester vibration of monosubstituted aromatic rings (Kezerle et al. 2018).

\section{Antimicrobial evaluation of naked and Schiff base/biochar composites}

There was variation in the level of microbial inhibition of the various samples derived from activated rice husk and plantain peels biochar and their Schiff base impregnated counterparts. The effect was observed against isolates of Escherichia coli, Staphylococcus, Pseudomonas, Aspergillus sp. and Candida sp. (Figs. 7 and 8). The inhibition potential of rice husk and plantain peels biochar immobilized with SALEN and ACACEN indicates that they are capped with the same bioactive compounds (flavonoids, tannins, phlobatannins, alkaloids, glycosides and terpenoids) initially present in the plants and are majorly responsible for their medicinal properties. These phytochemicals have been reported to exert multiple biological and pharmacological effects (antibacterial, antihypertensive, antidiabetic and anti-inflammatory activities and their bioactivity are responsible for the definite physiological effects exerted on the human body (Asuquo and Udobi 2016; Banji and Adebayo 2020). The susceptibility test against Escherichia coli showed that among the various samples, that SALEN immobilized plantain peel biochar has the highest inhibition value (Fig. 7). Generally, there was observed increase

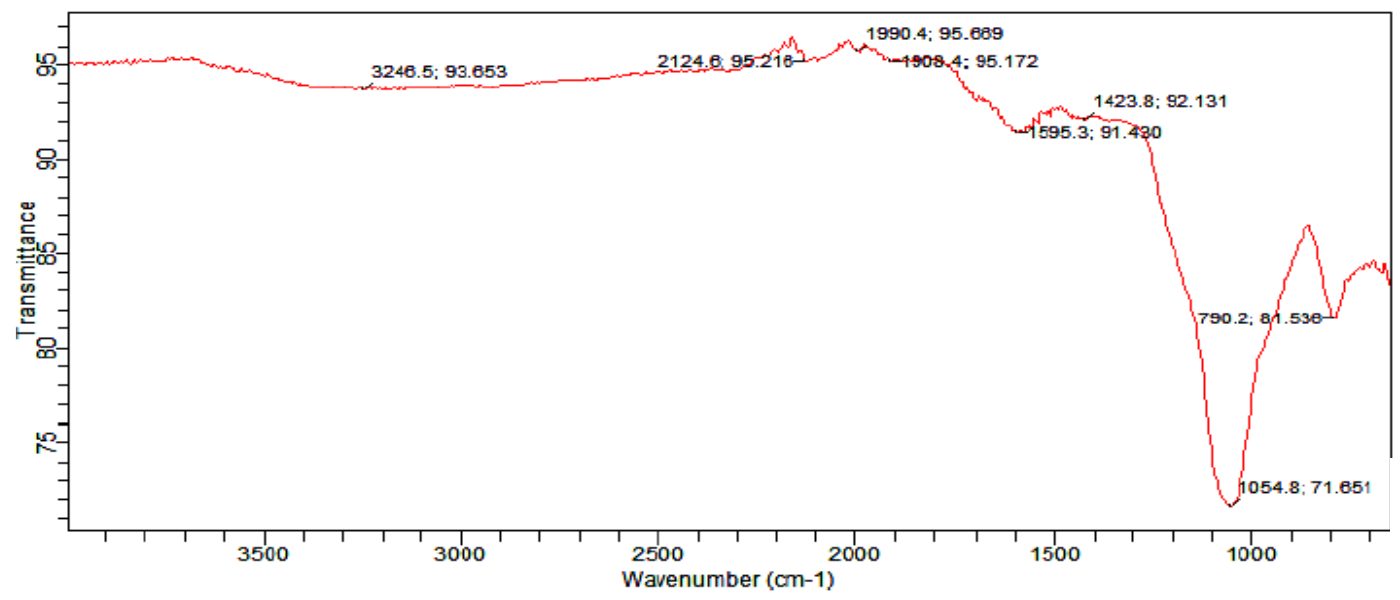

Fig. 6. FTIR spectra of activated rice husk biochar. 


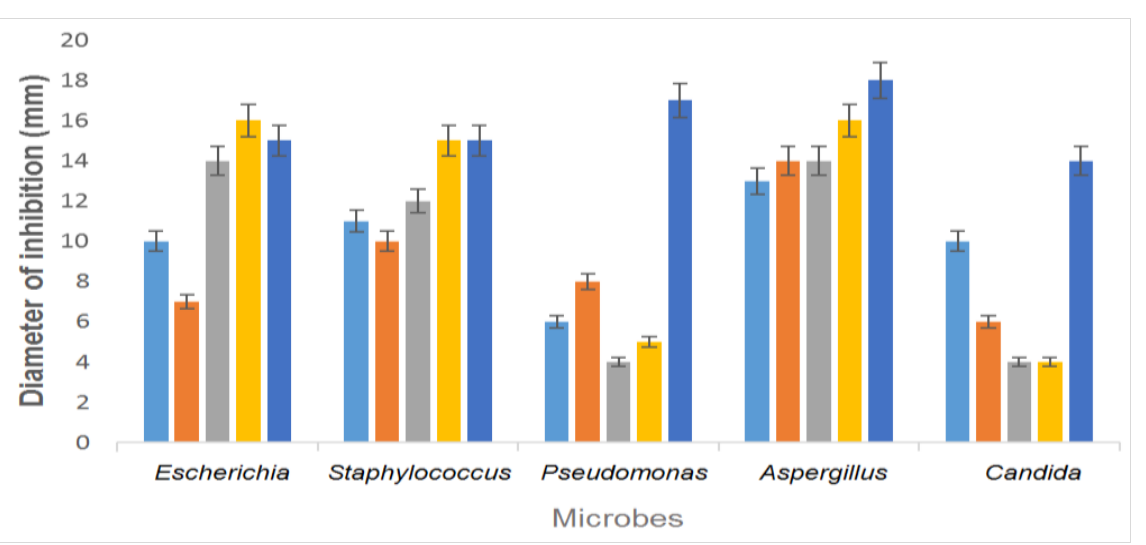

Fig. 7. Biocidal evaluation of naked biochar/SALEN biochar composites. $(\mathrm{ARHB}=$ Light blue, $\mathrm{APPB}=$ brown, $\mathrm{A}-\mathrm{ARHB}=$ silvery white, $\mathrm{A}-\mathrm{APPB}=$ yellow, Control $=$ deep blue). Data are given for controls, ARHB, APPB, A-ARHB and A-APPB. Antimicrobial tests were done with mean $\pm \operatorname{SD}(n=4)$. Values of the activated biochar and composites were presented at $P \leq 0.05$ level of significance.

in zone of inhibition for the SALEN Schiff base immobilized biochar compared to the naked biochar counterpart (Figs. 7 and 8). This observation could be explained by chelation theory as chelation increases the lipophilicity and denaturation of the cell wall of the micro-organism (Nworie et al. 2018). Similarly, the bioactivity increased due to ligation of the micro-organism cell wall bonds with the $-\mathrm{OH}$ group of the immobilized biomaterial and exchange of ions at the $-\mathrm{C}=\mathrm{O}$ interfaces of the impregnated biochar and bacterial cell well thereby increasing denaturation followed by cell death (Nworie and Nwabue 2017). There is perceived free radical generation when the Schiff base (SALEN or ACACEN) impregnated biochar was intercalatively co-ordinated to the cell of the micro-organism enhancing cell wall permeation, magnifying intracellular ATP leakage and quantitatively disrupting the activity functionality of DNA and RNA of the cells inducing cell death a confirmation of increased bactericidal activity The antimicrobial activity of SALEN immobilized. rice husk and plantain peel biochar shows that inhibitory diameter of 15 and $12 \mathrm{~mm}$ respectively was recorded against Staphylococcus isolate.
Quite low unexpected inhibition value of $4 \mathrm{~mm}$ and $5 \mathrm{~mm}$ (Fig. 7) against Pseudomonas was observed with SALEN immobilized rice husk and plantain peel biochar respectively. This could be due to reverse mechanism indicating that the process is not controlled by chelation but by overtone theory (Hsueh et al. 2017; Nworie et al. 2018). The inhibition value of Aspergillus sp. was $16 \mathrm{~mm}$ for immobilized plantain peel biochar whereas a very low value of inhibition was observed with all the biochar with Candida sp. The low inhibition could be attributed to the resistance of this organism and the relative reluctance of the biochar and immobilized biochar counterpart to cross over the cell membrane thereby decreasing the bioactivity. Generally, it could be observed that the rice husk biochar inhibited the growth of the selected microbes better than the plantain peels biochar. This could be attributed to the greater pore surface area and pore size of the rice husk biochar as supported by the BET analysis. Exceptional degree of inhibition of Aspergillus sp. $(19 \mathrm{~mm})$ was observed with the A-ARHB which was better than the control drug (ampiclox, $18 \mathrm{~mm}$ ) further confirming that ACACEN or SALEN

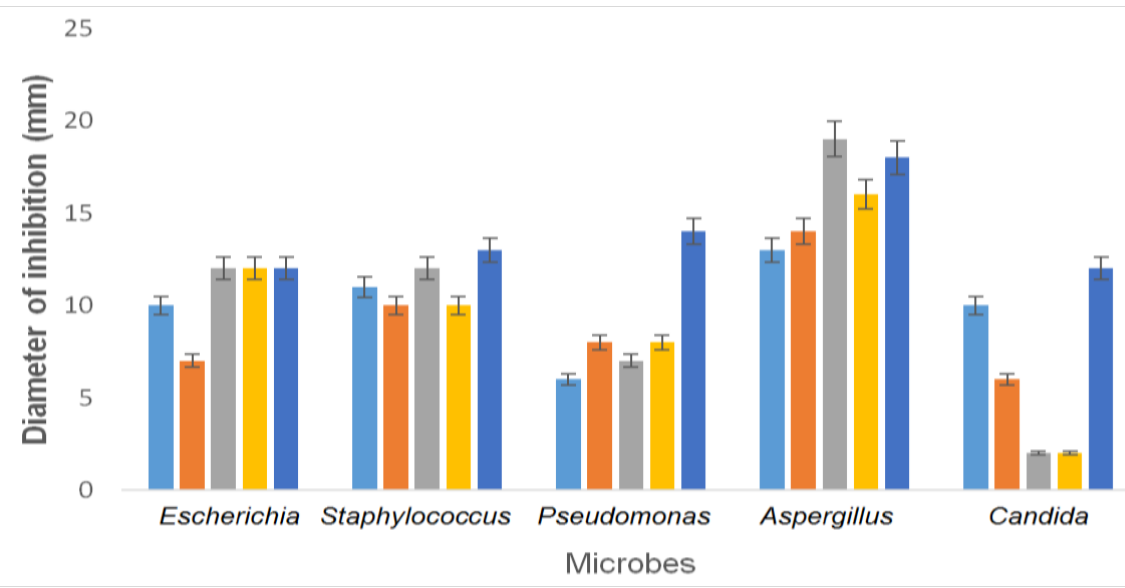

Fig. 8. Biocidal evaluation of naked biochar/ACACEN biochar composites. (ARHB = Light blue, $\mathrm{APPB}=$ brown, $\mathrm{A}-\mathrm{ARHB}=$ silvery white, $\mathrm{A}-\mathrm{APPB}=$ yellow, Control = deep blue). Data are given for controls, ARHB, APPB, A-ARHB and A-APPB. Antimicrobial tests were done with mean $\pm \mathrm{SD}(n=4)$. Values of the activated biochar and composites were presented at $P \leq 0.05$ level of significance. 
Table 2. MIC of activated biochar, SALEN and ACACEN composites.

\begin{tabular}{lclccc}
\hline Biochar/ composites & E. coli & Staphylococcus & Pseudomonas & Aspergillus & Candida \\
\hline ARHB & $15 \pm 0.01$ & $19 \pm 0.28$ & $16 \pm 0.31$ & $15 \pm 0.01$ & $14 \pm 0.24$ \\
APPB & $17 \pm 0.05$ & $20 \pm 0.42$ & $18 \pm 0.65$ & $16 \pm 0.01$ & $13 \pm 0.11$ \\
S-ARHB & $10 \pm 0.45$ & $12 \pm 0.07$ & $9 \pm 0.75$ & $11 \pm 0.02$ & $17 \pm 0.03$ \\
S-APPB & $11 \pm 0.50$ & $14 \pm 0.97$ & $10 \pm 0.64$ & $12 \pm 0.05$ & $16 \pm 0.09$ \\
A-ARHB & $9 \pm 0.02$ & $13 \pm 0.35$ & $7 \pm 0.46$ & $11 \pm 0.25$ & $17 \pm 0.28$ \\
A-APPB & $12 \pm 0.04$ & $13 \pm 0.36$ & $9 \pm 0.08$ & $13 \pm 0.56$ & $18 \pm 0.44$ \\
\hline
\end{tabular}

Data are given for ARHB, APPB, S-ARHB and S-APPB. Antimicrobial tests were done with mean \pm SD $(n=4)$. Values of MIC of the activated biochar and composites were presented at $P \leq 0.05$ level of significance.

functionalized ARHB is a better anti-bactericidal agent. Similar studies on the use of copper (I) oxide immobilized biochar shows that the functionalized nanocomposites presents itself as better biocidal agent than the naked nanoparticle biochar (Yang et al. 2019). The XRD diffractogram further supported the higher inhibitory diameter of rice husk biochar and its impregnated counterpart as it is amorphous as against plantain peel which is crystalline. Biochar in the amorphous state provides excellent and wider surface area for decimation of microbes (Yang et al. 2019). Considering the inhibition diameter of the activated biochar and composites, there was significant difference in the inhibition of Escherichia coli, Staphylococcus and Aspergillus between the positive control and the activated biochar and composites at $P \leq 0.05$. However, a clear investigation of the inhibition of pseudomonas and candidiasis revealed a slight difference at $P \leq 0.05$.

\section{Effect of naked biochar/composites concentration on the inhibition of microbes}

The minimum inhibitory concentration of test samples were determined by dispersing the naked biochar and composites in agar medium and on solidification, the various microbe cultures were inoculated on the agar-composite medium, incubated for $24 \mathrm{~h}$ in the temperature of $37{ }^{\circ} \mathrm{C}$. From Table 2 it could be observed that the minimum inhibitory concentration (MIC) of naked biochar are higher than those of the composites indicating that the composites are better bactericidal agent. Some authors (Yang et al. 2019) who evaluated the MIC of biochar modified with metal oxides observed that naked biochar have higher MIC compared with functionalized biochar, an indication of the composites nanostructures, which enhanced microbial cytoplasmic penetration and increased ROS generation leading to cell death. From Table 2, there is no significant difference in the MIC for the inhibition of the microbes between the naked biochar and Schiff base composites at $P \leq 0.05$. The values as recorded in Table 2 clearly indicated higher microbial action of the composites which could have resulted from the multiplex action of the increased functionalities. Consequently, it is advocated that for increased antimicrobial result with biochar, immobilization or functionalization of the surface is necessary.

\section{Mechanism of biocidal action of Schiff base/biochar composites}

The surface of the biochar and functionalized nanocomposite is basically positively charged whereas that of the bacterial membrane is negatively charged inducing electrostatic interaction catalyzed by increased surface area. The electrostatic interaction disrupts film, cell membrane structure and permeability and induces damage to bacterial proteins (Gao et al. 2017). Increased oxidative stress manifests with lysis, membrane instability, cell wall denaturation and death. Intercalation of functional groups especially sulfur containing groups to mesosomes inhibits DNA replication, cellular respiration, cell division and suffocation. Biochar on interacting with the microbial cell wall instigates the production of reactive oxygen species (ROS), such as superoxide anions $\left(\mathrm{O}_{2}^{-}\right)$, hydroxyl radicals $\left(\mathrm{OH}^{-}\right)$ and hydrogen peroxide $\left(\mathrm{H}_{2} \mathrm{O}_{2}\right)$ which are highly deleterious to microbial species. The ROS basically disintegrates biologically important species present in the micro-organisms, such as amino acids, 
proteins, lipids, carbohydrates and nucleic acids. Functionalization with introduction of oxygen and nitrogen functionalities leads to alteration in electronic properties and molecular size thereby inducing ROS production and multiplication (Varlamov 2005; Nworie et al. 2016; Nworie 2016; Kilonzo et al. 2018). Consequently, the electrondonor-acceptor characteristics common among multifunctional materials also enhances ROS production and multiplication through Fenton-type reaction (Yang et al. 2019). The high biocidal property of the nanocomposite is as a consequence of the positively charged surface of SALEN and ACACEN functionalized biochar containing oxygen and nitrogen containing group functionalities derived from the Schiff bases which electrostatically interacts with the negatively charged bacterial cell wall. This interaction leads to cell wall denaturation and death. The higher biocidal efficiency of the functionalized biochar could be as a result of the characteristic nano-size (from XRD and BET measurement), toxicity and shape. The biocidal mechanism of biochar and functionalized nanocomposite can be said to involve destruction and malfunctioning of cell well induced by metallic oxides on the biochar surface (XRD analysis implicated some metallic oxides, such as potassium oxide as a peak in the biochar), disturbance in electron transport and energy generation, production of ROS especially by incorporation of oxygen or nitrogen containing groups, inactivation of cell enzymes and inhibition of DNA replication.

\section{Regeneration/reusability of used biochar and Schiff base composites}

The fate of the used biochar and composites is important to prevent environmental contamination and also to determine the economy of the process. The regeneration and reusability ensures eco-friendliness and economic nature of used sorbents which are of high industrial importance. In the regeneration experiment, different acid $(\mathrm{HCl})$ concentrations $(1,0.5,0.1$ and $0.01 \mathrm{M}$ ) were used for the treatment of used biochar/ composites. The used biochar/composites were equilibrated in $5 \mathrm{~cm}^{3}$ acid solution for varied time of 5, 10, 15 and 20 min. Maximum microbial decimation from the used sorbent was observed at $1 \mathrm{M} \mathrm{HCl}$ and 10 min shaking and reusability up to four times obtained with only $15 \%$ decrease in effectiveness and efficiency.

\section{Conclusion}

This study evaluated the bactericidal activities of biochar derived from plantain peel and rice husk and their Schiff base functionalized counterpart. The results of the antimicrobial screening against five pathogenic microbes showed that the biochar and their Schiff base impregnated counterpart are very effective against Escherichia coli, Staphylococcus, Pseudomonas, Aspergillus and Candida sp. The generation of ROS on the surface of the microbes in contact with Schiff base functionalized activated biochar can be the main mechanism for antimicrobial potency or death of microbes. Evaluating the structure and size of the activated biochar revealed that amorphous biochar inhibited microbial growth than the crystalline biochar. Similarly, the Schiff base functionalized biochar are better biocidal agent than the naked biochar. The study indicated that at that there is no significant difference in the inhibition of microbes by naked and functionalized biochar at $P \leq 0.05$ level of significance. Regeneration and reusability of used biochar and composites indicated the fabricated materials as efficient, low cost and environmentally friendly.

\section{Acknowledgement}

The authors are grateful to Ebonyi State University, Abakaliki for TET Fund seed grant (Ref No: EBSU/TETFund/IBR/2016/10) financial assistance.

\section{Conflict of Interest}

The authors declare that they have no conflict of interest.

\section{References}

ALOthman ZA (2012) A Review: Fundamental aspects of silicate mesoporous materials. Materials 5: 2874-2902.

Asuquo EG, Udobi CE (2016) Antibacterial and toxicity studies of the ethanol extract of Musa paradisiaca leaf. Cogent Biol. 2: 1219248. 
Banerjee S, Chattopadhyaya M (2017) Adsorption characteristics for the removal of toxic dye, tartrazine from aqueous solutions by a low cost agricultural byproduct. Arab. J. Chem. 10: S1629-S1638.

Banji SA, Adebayo O (2020) Nutraceutical potential of ripe and unripe plantain peels: A comparative study. Chem. Inter. 6: 83-90.

Chen D, Wang X, Wang X, Feng K, Su J, Dong J (2020) The mechanism of cadmium sorption by sulphur-modified wheat straw biochar and its application cadmium contaminated soil: Sci. Total Environ. 714: 136-150.

Chen R, Zhao X, Jiao J, Li Y, Wei M (2019) Surfacemodified biochar with polydentate binding sites for the removal of cadmium. Int. J. Mol. Sci. 20: 1775-1785.

Gao Y, Pramanik A, Begum S, Sweet C, Jones S, Alamgir A, Ray PC (2017) Multifunctional biochar for highly efficient capture, identification and removal of toxic metals and superbugs from water samples. ACS Omega 2: 7730-7738.

Ghorbani M, Eisazadeh H (2015) Removal of COD, color, anions and heavy metals from cotton textile wastewater by using polyaniline and polypyrrole nanocomposites coated on rice husk ash. Compos. B Eng. 45: 1-7.

Hsueh YH, Tsai PH, Lin KS, Ke WJ, Chiang CL (2017) Antimicrobial effects of zero-valent iron nanoparticles on Gram-positive Bacillus strains and Gram-negative Escherichia coli strains. J. Nanobiotech. 15: 77.

Jindapon W, Jaiyen S, Ngamcharussrivichai C (2015) $\mathrm{Al}_{2} \mathrm{O}_{3}$ supported mixed $\mathrm{Ca}$ and $\mathrm{Zn}$ compounds prepared from waste seashells for synthesis of palm fatty acid methyl esters. Chem. Eng. Commun. 202: 1591-1599.

Kala A, Soosairaj S, Mathiyazhagan S, Raja P (2015) Isolation and identification of Xanthomonas oryzae pv. oryzae the causal agent of rice bacterial leaf blight and its activities against of six medicinal plants. Asian J. Plant Sci. Res. 5: 80-83.

Kezerle A, Velic N, Hasenay KD (2018) Lignocellulosic materials as adsorbents: Adsorption of MEB and Congo red on brewers spent grain. Croat. Chem. Acta. 91: 53-64.

Kilonzo JK, Ochoo L, Maingi JM, Swaleh S, Njue WM (2018) Sonochemical biosynthesis of silver nanoparticle using Bridelia micrantha and evaluation of their antibacterial activity. EIJST 7: 1-13.

Nworie FS (2016) Bis(salicylidene)ethylenediamine(salen) and Bis(salicylidene)ethylenediamine-metal complexes: From structure to biological activity. J. Anal. Pharm. Res. 3: $76-86$

Nworie FS (2018) Spectral, thermal and in vitro antibacterial studies on cadmium(II)-bis(2,2-methylidenephenol) diaminoethane. J. Turk. Chem. Soc. Sect. A 5: 1029-1036.

Nworie FS, Nwabue F, Ikelle I, Ogah A, Elom N, Ilochi N, Itumoh E, Oroke C (2018) Activated plantain peel biochar as adsorbent for sorption of Zinc (II) ions: Equilibrium and kinetic studies. J. Turk. Chem. Soc. Sect. A. 5: 12571270.

Nworie FS, Nwabue FI (2017) Synthesis, optimization, characterization and antimicrobial studies of $\mathrm{Cu}(\mathrm{II})$ and $\mathrm{Co}$ (III) complexes of bis(2,2/-methylylidenephenol) diaminoethane. Chem. J. Moldova. 12: 41-49.

Nworie FS, Nwabue FI, Elom NI, Eluu S (2016) Schiff bases and Schiff base metal complexes: From syntheses to applications. J. Basic Appl. Res. 2: 295-305.

Nworie FS, Nwabue FI, Oti W, Omaka NO, Igwe H (2020) Hydrothermal synthesis of multifunctional biocharsupported SALEN nanocomposite for adsorption of Cd(II) ions: Function, mechanism, equilibrium and kinetic studies. Anal. Bioanal. Chem. Res. 8: 91-112.

Nworie S, Nwabue FI, Oti W, Mbam E, Nwali BU (2019) Removal of methylene blue from aqueous solution using activated rice husk biochar: Adsorption isotherms, kinetics and error analysis. J. Chil. Chem. Soc. 64: 43654376.

Okareh OT, Adeolu AT, Adepoju OT (2015) Proximate and mineral composition of plantain (Musa paradisiaca) wastes flour; a potential nutrient source in the formation of animal feeds. Afr. J. Sci. Tech. 6: 53-57.

Pulido-Novicio L, Kurimoto Y, Aoyama M, Seki K, Doi S, Hata T, Ishihara S, Imamura $Y($ 2001) Sorption of mercury by sugi wood carbonized at $1000{ }^{\circ} \mathrm{C}$. J. Wood. Sci. 47: 159-162.

Tang W, Cai N, Xie H, Liu Y, Wang Z, Liao Y, Wei T, Zhang C, Fu Z, Yin D (2020) Efficient adsorption removal of $\mathrm{Cd}^{2+}$ from aqueous solutions by $\mathrm{HNO}_{3}$ modified bamboo-derived biochar. IOP Conf. Ser., Mat. Sci. Eng. 729: 012081.

Varlamov VP (2005) Ultrastructural study of chitosan effects on Klebsiella and Staphylococci. Bull. Exp. Biol. Med. 140: 356-360.

Yang Z, Hao X, Chen S, Ma Z, Wang W, Wang C, Yue L, Sun H, Shao Q, Murugadoss V (2019) Long-term antibacterial stable reduced graphene oxide nanocomposites loaded with cuprous oxide nanoparticles. J. Colloid Interface Sci. 533: 13-23.

Zhang L, Guo J, Huang X, Wang W, Sun P, Lib Y, Han J (2019) Functionalized biochar-supported magnetic $\mathrm{MnFe}_{2} \mathrm{O}_{4}$ nanocomposite for the removal of $\mathrm{Pb}(\mathrm{II})$ and Cd(II). RSC Adv. 9: 365-376.

Zhao G, Li J, Ren X, Chen C, Wang X (2011) A few-layered graphene oxide nanosheets as superior sorbents for heavy metal ion pollution management. Environ. Sci. Technol. 45: 10454-10462.

Zhao J, Niu Y, Ren B, Chen H, Zhang S, Jin J, Zhang Y (2018) Synthesis of Schiff base functionalized super paramagnetic $\mathrm{FeZO}_{4}$ composites for effective removal of $\mathrm{Pb}$ (II) and $\mathrm{Cd}(\mathrm{II})$ from aqueous solution. Chem. Eng. J. 347: 574-584. 